\title{
Validity of simplified, calibration-less exercise intensity measurement using resting heart rate during sleep: a method- comparison study with respiratory gas analysis
}

Hirotaka Matsuura', Masahiko Mukaino ${ }^{1 *}$ (D), Yohei Otaka ${ }^{1}$, Hitoshi Kagaya ${ }^{1}$, Yasushi Aoshima², Takuya Suzuki², Ayaka Inukai ${ }^{2}$ Emi Hattori², Takayuki Ogasawara ${ }^{3}$ and Eiichi Saitoh ${ }^{1}$

\begin{abstract}
Background: The recent development of wearable devices has enabled easy and continuous measurement of heart rate (HR). Exercise intensity can be calculated from HR with indices such as percent HR reserve (\%HRR); however, this requires an accurate measurement of resting HR, which can be time-consuming. The use of HR during sleep may be a substitute that considers the calibration-less measurement of \%HRR. This study examined the validity of \%HRR on resting HR during sleep in comparison to percent oxygen consumption reserve $\left(\% \mathrm{VO}_{2} \mathrm{R}\right)$ as a gold standard. Additionally, a 24/7\%HRR measurement using this method is demonstrated.
\end{abstract}

Methods: Twelve healthy adults aged $29 \pm 5$ years underwent treadmill testing using the Bruce protocol and a 6 -min walk test $(6 \mathrm{MWT})$. The $\% \mathrm{VO}_{2} \mathrm{R}$ during each test was calculated according to a standard protocol. The \%HRR during each exercise test was calculated either from resting HR in a sitting position (\%HRR $\mathrm{H}_{\text {sitting}}$ ), when lying awake (\%HRR ying $_{\text {ly }}$ ), or during sleep (\%HRR sleeping). Differences between $\% \mathrm{VO}_{2} \mathrm{R}$ and $\% \mathrm{HRR}$ values were examined using Bland-Altman plots. A 180-day, 24/7\%HRR measurement with three healthy adults was also conducted. The \%HRR values during working days and holidays were compared.

Results: In the treadmill testing, the mean difference between $\% \mathrm{VO}_{2} \mathrm{R}$ and $\% \mathrm{HRR}_{\text {sleeping }}$ was $1.7 \%$ (95\% confidence interval $[\mathrm{Cl}],-0.2$ to $3.6 \%)$. The $\% \mathrm{HRR}_{\text {sitting }}$ and $\% \mathrm{HRR}_{\text {lying }}$ values were $10.8 \%(95 \% \mathrm{Cl}, 8.8$ to $12.7 \%)$ and $7.7 \%$ (95\% Cl, 5.4 to $9.9 \%)$, respectively. In the $6 \mathrm{MWT}$, mean differences between $\%_{\mathrm{VO}} \mathrm{R}$ and $\% \mathrm{HRR}_{\text {sitting, }} \% \mathrm{HRR}_{\text {lying }}$ and $\% H_{R R}$ sleeping were $12.7 \%(95 \% \mathrm{Cl}, 10.0$ to $15.5 \%), 7.0 \%(95 \% \mathrm{Cl}, 4.0$ to $10.0 \%)$ and $-2.9 \%(95 \% \mathrm{Cl},-5.0 \%$ to $-0.7 \%$ ), respectively. The 180 -day, $24 / 7 \% H R R$ measurement presented significant differences in \%HRR patterns between working days and holidays in all three participants.

Conclusions: The results suggest $\% \mathrm{HRR}_{\text {sleeping }}$ is valid in comparison to $\%_{\mathrm{VO}} \mathrm{R}$. The results may encourage a calibration-less, 24/7 measurement model of exercise intensity using wearable devices.

Trial registration: UMIN000034967.

Registered 21 November 2018 (retrospectively registered).

Keywords: Heart rate, Wearable devices, Percent oxygen consumption reserve, Exercise intensity, 6-min walk test

\footnotetext{
* Correspondence: mmukaino@fujita-hu.ac.jp

${ }^{1}$ Department of Rehabilitation Medicine I, School of Medicine, Fujita Health

University, Toyoake, Japan

Full list of author information is available at the end of the article
}

(c) The Author(s). 2019 Open Access This article is distributed under the terms of the Creative Commons Attribution 4.0 International License (http://creativecommons.org/licenses/by/4.0/) which permits unrestricted use, distribution, and reproduction in any medium, provided you give appropriate credit to the original author(s) and the source, provide a link to the Creative Commons license, and indicate if changes were made. The Creative Commons Public Domain Dedication waiver (http://creativecommons.org/publicdomain/zero/1.0/) applies to the data made available in this article, unless otherwise stated. 


\section{Background}

The measurement of exercise intensity can be used to monitor energy consumption or appropriate workloads during exercise [1]. Oxygen consumption $\left(\mathrm{VO}_{2}\right)$ and heart rate (HR) can be used to assess exercise intensity [2]. Using respiratory gas analyzers, exercise intensity can be assessed with indices such as percent $\mathrm{VO}_{2}$ reserve $\left(\% \mathrm{VO}_{2} \mathrm{R}\right)$ or percent maximum $\mathrm{VO}_{2}$ [3]. These indices are usually evaluated during exercise testing (e.g., the Bruce protocol or the Balke protocol) and are used when prescribing exercises [4, 5]. Indices of exercise intensity during exercise testing provide accurate information on an individual's cardiovascular and pulmonary capacity for a specific workload. However, such testing requires specialized settings. In addition, these tests are sometimes difficult to perform for individuals with disabilities, because limited mobility may mask cardiovascular and respiratory aspects of functional capacity.

$\mathrm{HR}$ is widely used to monitor exercise intensity $[6,7]$. In particular, percent $H R$ reserve (\%HRR) is frequently used as an index of exercise intensity [8] and has been correlated and is in good agreement with $\% \mathrm{VO}_{2} \mathrm{R}$, although \%HRR seems to be slightly lower in low exercise intensities $[9,10]$. Both $\% \mathrm{VO}_{2} \mathrm{R}$ and $\% \mathrm{HRR}$ are suitable measures for exercise prescription $[11,12]$. The merit of using HR lies in its ease of use; it can be monitored in various settings and is not limited to specialized settings. In addition to their HR during exercise, an individual's resting and maximum $H R$ are needed to calculate \%HRR. The maximum HR should ideally be measured by exercise testing, but there is an easy alternative method to estimate maximum HR with a simple equation using an individual's age [13]. On the other hand, the resting HR should actually be measured, and the accuracy of resting HR is important for precise calculation of the exercise intensity. HR can easily be influenced by mental state at the time of measurement and/or activities immediately before measurement. Therefore, sufficient premeasurement rest and abstention from exercise is needed to obtain an accurate resting HR [14]. However, in usual clinical settings, it may not always be possible to provide sufficient time for a subject for resting HR measurement. One possible solution may be to measure the HR during sleep, which should be lower and more stable than that during the awake condition [15]. Recording HR during sleep may present less measurement errors related to psychological or physical factors, which are difficult to eliminate when the measurements are taken while the individual is awake. In addition, longer periods of HR measurement may improve the accuracy of resting HR measurements. Recent technological developments have enabled the easy monitoring of HR using wearable devices. For example, wrist-band type measurement devices or smart clothing systems have reportedly enabled the continuous monitoring of HR [16-18]. The use of such technologies also enables the measurement of $\mathrm{HR}$ during sleep $[19,20]$. If \%HRR with the HR measured during sleep considered as the resting $\mathrm{HR}$ is validated, extra efforts taken to accurately measure the resting $\mathrm{HR}$ may not be necessary; thus, daily measurement of exercise intensity would be more feasible in the daily clinic. Additionally, this may further enable the 24/7 measurement of exercise intensity.

One of the major effects of exercise is the improvement of fitness, which is linked with the amount of exercise and exercise intensity [21, 22]. To increase the amount of exercise and exercise intensity on a daily basis, not only the scheduled exercise, but also the daily activities other than the scheduled exercise, should be increased. Therefore, continuous monitoring of the activities may be of great significance. If the activities could be measured $24 \mathrm{~h}$ a day every day, it would be easier to find a critical and effective solution to increase the amount and intensity of exercise on a daily basis, which will contribute to improve the fitness of the individuals.

In this context, this study aimed to examine the validity of \%HRR, calculated with a simplified method using resting $\mathrm{HR}$ measured during sleep, against $\% \mathrm{VO}_{2} \mathrm{R}$ (the gold standard), in a healthy subject. The measurements were performed during two kinds of exercising; treadmill testing with the Bruce protocol and a 6-min walk test (6MWT). In addition, the feasibility of the 24/7 measurement of exercise intensity with the use of this method was tested in healthy subjects.

\section{Methods \\ Validity study \\ Participants}

In the validity study, 12 healthy adults (eight males; mean age, $29 \pm 5$ years) participated. The individuals 1 ) without any medical history of diseases which could affect cardiorespiratory fitness and movement function, such as heart failure, myocardial infarction, bone fracture, and spinal cord injury and 2) who agreed to wear the measuring devices during the entire 2-day measurement session after checking the fit of the wearable devices. Non-probability sampling procedures were used to recruit a convenience sample of participants. The exclusion criteria were 1) existence of sleep disturbance and 2) medication which could potentially affect performance. Participants' height and weight were $166.2 \pm 8.6 \mathrm{~cm}$ and $59.1 \pm 10.8 \mathrm{~kg}$, respectively.

The study protocol was approved by the Medical Ethics Committee of Fujita Health University. All participants provided written informed consent before participation.

\section{Procedures and measurements}

Validity study In the validity study, each participant performed treadmill testing with the Bruce protocol [4] and a 6MWT. The participants were asked to avoid high 
intensity exercise and alcohol and caffeine $24 \mathrm{~h}$ before the measurement session.

Before treadmill testing and the 6MWT, resting HR and $\mathrm{VO}_{2}$ while sitting and while lying were measured after a 10-min sitting interval. Lying and sitting HR were measured with a 5-min interval in a random order to eliminate order effect bias. An average resting HR value of $3 \mathrm{~min}$ was used for the analyses. Then, in the 6MWT, participants were instructed to walk at a comfortable speed for $6 \mathrm{~min}$. After a 15-min rest, treadmill exercise testing with the Bruce protocol was conducted. In this experiment, we considered the VO2 and HR to be maximum if the participants satisfied at least three of the following four criteria: 1) maximum voluntary exhaustion as measured by the Borg CR-10 scale; 2) presence of an HR plateau ( $\Delta \mathrm{HR}$ between two consecutive work rates $\leq 4$ beats. $\left.\min ^{-1}\right)$; 3 ) presence of a VO2 plateau $(\triangle \mathrm{VO} 2$ between two consecutive work rates $\left.<2.1 \mathrm{~mL} \cdot \mathrm{kg}^{-1} \cdot \mathrm{min}^{-1}\right)$; and 4) a maximal respiratory exchange ratio $(\mathrm{RERmax})>1.1[10,23]$.

Respiratory gas analysis during exercise testing was performed with a Mobile Aero Monitor AE-100i (MINATO Medical Science, Tokyo, Japan). HR was measured using a hitoe or 'smart clothing' system (NTT corp., Tokyo, Japan and Toray corp. Kyoto, Japan). This consisted of hitoe wear, a hitoe transmitter, and a smartphone application. An accelerometer embedded in the hitoe transmitter estimated trunk posture (lying or not). Participants wore hitoe wear during the measurements and the nights before and after the exercise testing. Participants were instructed to go to bed by midnight on these nights. Sleep time was defined as the time when the participant was in the supine position, as judged with the accelerometer, between midnight and $5 \mathrm{a} . \mathrm{m}$. The average of HR between the two nights was used as the sleeping HR. None of the participants reported sleep disorder during the measurement.

\section{Analyses}

The \%HRR was calculated using the equation:

$$
\% H R R=(H R-\text { restingHR }) /
$$

$\{$ MaxHR during treadmill testing-restingHR $\}$

In the validity study, $\mathrm{HR}$ in a sitting position $\left(\mathrm{HR}_{\mathrm{sitting}}\right)$, when lying awake ( $\left.\mathrm{HR}_{\text {lying }}\right)$, or during sleep $\left(\mathrm{HR}_{\text {sleeping }}\right)$ were used as the value of resting $\mathrm{HR}$. The actual maximum value (HRmax) was obtained during the treadmill exercise testing.

The $\% \mathrm{VO}_{2} \mathrm{R}$ was calculated with the equation:

$$
\begin{aligned}
& \% \mathrm{VO}_{2} \mathrm{R}=\left(\mathrm{VO}_{2} \text {-resting } \mathrm{VO}_{2}\right) / \\
& \text { (MaximumVO } \left.\mathrm{O}_{2} \text { during treadmill testing-resting } \mathrm{VO}_{2}\right) \text {. }
\end{aligned}
$$

The $\mathrm{VO}_{2}$ value during sitting and maximum $\mathrm{VO}_{2}$ value during treadmill exercise testing with the Bruce protocol were used for resting and maximum $\mathrm{VO}_{2}$, respectively.
The $\% \mathrm{HRR}$ and $\% \mathrm{VO}_{2} \mathrm{R}$ data used for the analyses were the averaged \%HRR and $\% \mathrm{VO}_{2} \mathrm{R}$ measured during the middle 1 min of each 3-min stage during the treadmill testing and the averaged $\% \mathrm{HRR}$ and $\% \mathrm{VO}_{2} \mathrm{R}$ measured during the first, third, and the last minutes of the 6MWT. One-way repeated measures analysis of variance (ANOVA) with post-hoc multiple comparisons was performed to examine if there were differences between $\mathrm{HR}_{\text {sitting, }} \mathrm{HR}_{\text {lying }}$ and

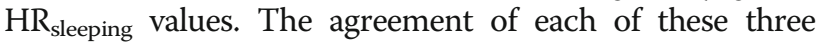
types of \%HRR with $\% \mathrm{VO}_{2} \mathrm{R}$ was examined with a BlandAltman plot $[24,25]$ for each exercise test.

Fixed and proportional biases were evaluated. Fixed bias was computed as the average difference between $\% \mathrm{HRR}$ and $\% \mathrm{VO}_{2} \mathrm{R}$, statistically checked by the $95 \%$ confidence interval $(\mathrm{CI})$ of the mean differences between the two values $(\overline{\mathrm{d}})$. Fixed bias was indicated if the $95 \% \mathrm{CI}$ of $\overline{\mathrm{d}}$ did not include zero. Proportional bias was expressed as the correlation coefficient between the difference and average of $\% \mathrm{HRR}$ and $\% \mathrm{VO}_{2} \mathrm{R}$. When there was proportional bias, the magnitude of the difference between the two values changed depending on the magnitude of the mean of the two values in the Bland-Altman plot. LOA and $95 \%$ confidence intervals (CI) around the LOA were calculated using the modified method for a Bland-Altman analysis with multiple observations per individual $[26,27]$.

Statistical analyses were performed using JMP11 (SAS Institute Inc., Cary, NC, USA). P-values $<0.05$ were considered statistically significant.

\section{4/7\%HRR measurement session Participants}

In the 24/7 measurement session, three healthy adults (all male, aged 33, 27, and 27, respectively) without any medical history of cardiorespiratory, orthopedic, or neurological diseases participated. The occupations of the participants were medical doctor, physical therapist, and occupational therapist.

\section{Procedure}

For the $24 / 7 \%$ HRR measurement session, the hitoe system was used for continuous monitoring of HR. Each participant wore the hitoe wear to monitor HR. For each participant, four pieces of hitoe wear were provided, so that they could wash and change the wear. The participants were told that they could take off the wear or transmitter while bathing or whenever they did not want to monitor HR. The observation was performed for consecutive 180 days.

\section{Analysis}

The \%HRR was calculated with HR during sleep as resting HR. The maximum $\mathrm{HR}$ was estimated using the Gellish equation $(H R \max =206.9-0.67 \times$ age $)$ [11] 
The daily time course of \%HRR was compared between working days and holidays. Working days in this experiment were defined as the days when the subjects were at work at for least $8 \mathrm{~h}$ a day, while holidays were defined as the days on which the participants were completely off duty. Days with less than 8 h' work was excluded from the analysis.

The \%HRR data was averaged for every $20 \mathrm{~s}$, and then the ensemble average, i.e., the average of each time point through all the observation periods, was calculated for the working days and holidays. The paired t-test was used for comparison between the HR on working days and holidays in each participant.

\section{Results}

\section{Validity study}

The resting HR during sitting, lying, and sleeping were $85 \pm 8,77 \pm 9$, and $58 \pm 5$ per minute, respectively.

The total number of data points used for Bland-Altman plots were 65 in treadmill testing and 36 in 6MWT. HR during sleep $\left(\mathrm{HR}_{\text {sleeping }}\right)$ was significantly lower than $\mathrm{HR}$ while awake (sitting and lying; $\mathrm{HR}_{\text {sitting }}$ and $\mathrm{HR}_{\text {lying}}$ ). The Bland-Altman plots showed the LOAs between \%HRR and $\% \mathrm{VO}_{2} \mathrm{R}$ during each exercise test (Fig. 1, Table 1). In the treadmill exercise testing, the mean differences between $\% \mathrm{VO}_{2} \mathrm{R}$ and \%HRR calculated with $\mathrm{HR}_{\text {sitting, }} \mathrm{HR}_{\text {lying, }}$ and

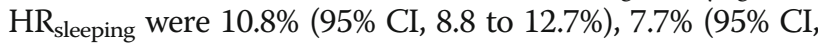
5.4 to $9.9 \%$ ), and $1.7 \%$ (95\% CI, -0.2 to $3.6 \%$ ), respectively (Fig. 1a-c). Significant differences between $\% \mathrm{VO}_{2} \mathrm{R}$ and $\% H R R$, calculated with $\mathrm{HR}_{\text {sitting }}$ and $\mathrm{HR}_{\text {lying, were observed, }}$ indicating fixed bias. There was no significant difference between $\% \mathrm{VO}_{2} \mathrm{R}$ and $\% \mathrm{HRR}$ calculated with $\mathrm{HR}_{\text {sleeping. }}$.

The $95 \%$ LOAs between $\% \mathrm{VO}_{2} \mathrm{R}$ and \%HRRs calculated with $\mathrm{HR}_{\text {sitting, }} \mathrm{HR}_{\text {lying, }}$ and $H R_{\text {sleeping }}$ were -5.4 to $27.0 \%,-11.4$ to $26.8 \%$, and -13.7 to $17.2 \%$, respectively. Proportional bias was found between $\% \mathrm{VO}_{2} \mathrm{R}$ and \%HRR calculated with $\mathrm{HR}_{\text {sitting }}(\mathrm{r}=-0.45, P<0.01)$. No significant proportional bias was observed between $\% \mathrm{VO}_{2} \mathrm{R}$ and $\% \mathrm{HRR}$ when calculated with $\mathrm{HR}_{\text {lying }}(\mathrm{r}=-0.18, P=$ $0.14)$ and $\mathrm{HR}_{\text {sleeping }}(\mathrm{r}=0.24, P=0.06)$.

In the $6 \mathrm{MWT}$, mean differences between $\% \mathrm{VO}_{2} \mathrm{R}$ and \%HRR calculated with $\mathrm{HR}_{\text {sitting }}, \mathrm{HR}_{\text {lying, }}$ and $\mathrm{HR}_{\text {sleeping }}$

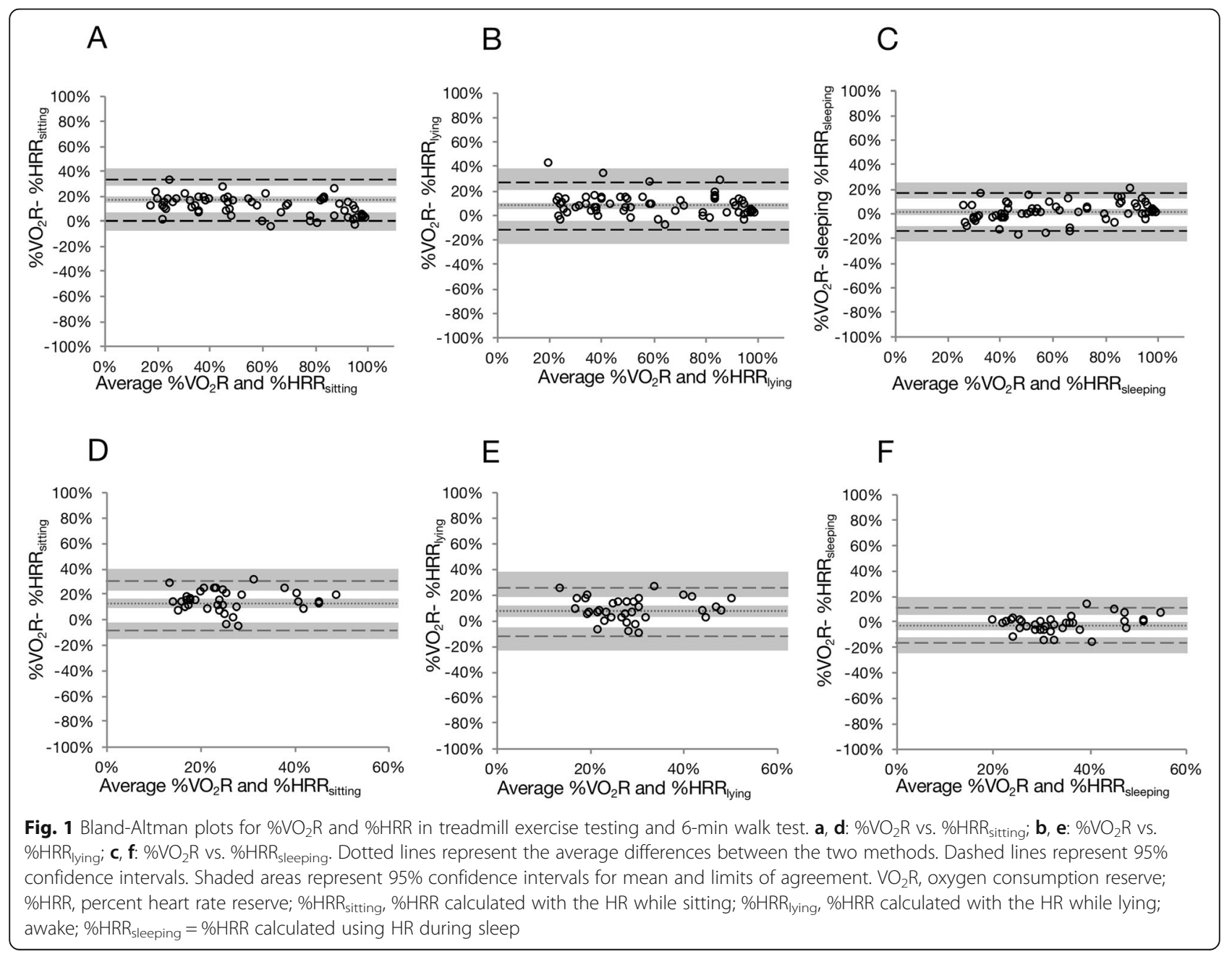


Table 1 Fixed and proportional bias in the Bland-Altman analysis

\begin{tabular}{|c|c|c|c|c|c|c|c|c|c|c|}
\hline & \multirow{3}{*}{$\begin{array}{l}\% \mathrm{VO}_{2} \mathrm{R} \\
\text { vs. \%HRR } \\
\text { based on }\end{array}$} & \multicolumn{7}{|l|}{ Fixed bias } & \multirow{2}{*}{\multicolumn{2}{|c|}{ Proportional bias }} \\
\hline & & \multirow{2}{*}{$\begin{array}{l}\text { Mean } \\
\text { difference }\end{array}$} & \multirow[t]{2}{*}{$95 \% \mathrm{Cl}$} & \multirow[t]{2}{*}{$P$} & \multirow{2}{*}{$\begin{array}{l}\text { Lower } \\
\text { LOA }\end{array}$} & \multirow[t]{2}{*}{$95 \% \mathrm{Cl}$} & \multirow{2}{*}{$\begin{array}{l}\text { Upper } \\
\text { LOA }\end{array}$} & \multirow[t]{2}{*}{$95 \% \mathrm{Cl}$} & & \\
\hline & & & & & & & & & $r$ & $P$ \\
\hline \multirow{3}{*}{$\begin{array}{l}\text { Treadmill testing with } \\
\text { Bruce protocol }\end{array}$} & $\mathrm{HR}_{\text {sitting }}$ & 10.8 & $8.8,12.7$ & $<0.0001$ & -5.4 & $-13.4,0.0$ & 27.0 & $22.5,35.0$ & -0.45 & $<0.01$ \\
\hline & $H R_{\text {lying }}$ & 7.7 & $5.4,9.9$ & $<0.0001$ & -11.4 & $-23.5,-4.9$ & 26.8 & $20.3,38.8$ & -0.18 & 0.14 \\
\hline & $H R_{\text {sleeping }}$ & 1.7 & $-0.2,3.6$ & 0.2552 & -13.7 & $-25.3,-9.3$ & 17.2 & $12.7,25.3$ & 0.24 & 0.06 \\
\hline \multirow[t]{3}{*}{ Six minutes walking test } & $H R_{\text {sitting }}$ & 12.7 & $10.0,15.5$ & $<0.0001$ & -5.0 & $-16.0,0.0$ & 30.4 & $24.3,41.4$ & 0.00 & 0.98 \\
\hline & $H R_{\text {lying }}$ & 7.0 & $4.0,10.0$ & $<0.0001$ & -11.6 & $-23.5,-5.0$ & 25.6 & $18.9,37.5$ & 0.02 & 0.90 \\
\hline & $H R_{\text {sleeping }}$ & -2.9 & $-5.0,-0.7$ & 0.0492 & -16.3 & $-24.6,-11.6$ & 10.5 & $5.9,18.9$ & 0.26 & 0.11 \\
\hline
\end{tabular}

$\mathrm{HR}$, heart rate; $\mathrm{LOA}$, limit of agreement; $\mathrm{Cl}$, confidence interval; $\% \mathrm{VO}_{2} \mathrm{R}$, percent oxygen consumption reserve; \% $\mathrm{HRR}$, percent heart rate reserve, $\mathrm{HR}$ sitting; resting $\mathrm{HR}$ at sitting awake, $\mathrm{HR}_{\text {sitting; }}$ resting $\mathrm{HR}$ at sitting awake, $\mathrm{HR}_{\text {lying; }}$; resting $\mathrm{HR}$ at lying awake, $\mathrm{HR}_{\text {sleeping; }}$ resting $\mathrm{HR}$ during sleeping

were $12.7 \%$ (95\% CI, 10.0 to $15.5 \%$ ), $7.0 \%$ (95\% CI, 4.0 to $10.0 \%$ ), and $-2.9 \%(95 \% \mathrm{CI},-5.0 \%$ to $-0.7 \%)$, respectively. There were significant differences between $\% \mathrm{VO}_{2} \mathrm{R}$ and \%HRR calculated with $\mathrm{HR}_{\text {sitting }}, \mathrm{HR}_{\text {lying, }}$ and $\mathrm{HR}_{\text {sleeping. }}$ LOAs between $\% \mathrm{VO}_{2} \mathrm{R}$ and \%HRR calculated with $\mathrm{HR}_{\text {sitting, }}$ $\mathrm{HR}_{\text {lying, }}$, and $\mathrm{HR}_{\text {sleeping }}$ were -5.0 to $30.4 \%,-11.6$ to $25.6 \%$ and -16.3 to $10.5 \%$, respectively (Fig. $1 \mathrm{~d}-\mathrm{f}$ ). No proportional biases were found between $\% \mathrm{VO}_{2} \mathrm{R}$ and \%HRR (Table 1).

\section{4/7 Measurement session}

To confirm the feasibility of the 24/7 measurement of exercise intensity with the wearable system and sleeping HR-based exercise intensity measurement, 24/7 measurement of $H R$ in three healthy subjects were performed. The results of 24/7 measurement of HR are shown in Fig. 2. The data was successfully acquired for 132, 142, and 165 days, respectively (working days: 102, 108, 123 days, holidays: 30, 34, 42 days). The graphs show the ensemble average and standard deviation of the $\% \mathrm{HRR}_{\text {sleeping }}$ values of each participant on working days and holidays. In all participants, the average HR values on working days were significantly higher $(P<0.0001)$ than HR values measured on holidays ( $17.8 \pm 14.6$ vs $14.6 \pm 13.9$, $14.6 \pm 14.4$ vs $12.9 \pm 12.6$, and $14.5 \pm 11.8$ vs $10.3 \pm 9.7$, respectively. The difference in average HR values were more evident during daytime $(9 \mathrm{am}-5 \mathrm{pm}, 26.0 \pm 10.9$ vs $21.2 \pm$ $12.7 \mathrm{P}<0.0001,23.7 \pm 11.5$ vs $21.7 \pm 10.2 \mathrm{P}<0.0001$, $22.3 \pm 6.8$ vs $16.3 \pm 6.8 \mathrm{P}<0.0001$, respectively).

\section{Discussion}

The present results showed that the \%HRR with sleeping $\mathrm{HR}$ was comparable with $\% \mathrm{VO}_{2} \mathrm{R}$, showing the least amount of errors against the $\% \mathrm{VO}_{2} \mathrm{R}$ value among $\%$ HRR values investigated in this study. In addition, the experiment monitoring \%HRR for 180 consecutive days presents the differences in the daily patterns of exercise intensity between the working days and holidays in each participant, demonstrating the feasibility of this method to monitor exercise intensity.
The results of the current study validated the \%HRR ing with $\% \mathrm{VO}_{2} \mathrm{R}$ as the gold standard. The results show the possible superiority of $\% \mathrm{HRR}_{\text {sleeping }}$ to $\% \mathrm{HRR}_{\text {sitting, which is }}$ more commonly used in exercise intensity calculations. Several factors possibly contribute to these results. First, psychological and physical factors that may influence $H R$, via the autonomic nervous system [28, 29], are eliminated during sleep. For example, mental stress may result in sympathetic nerve activity and increase HR [30]. Exercise also increases HR, even after cessation of exercise, which is influenced by activity of the sympathetic and parasympathetic nervous systems [31]. The influence of these factors could be removed during sleep. Second, increased stroke volume (SV) in a supine position may contribute to HR better reflecting the change in oxygen consumption. Based on Fick's principle [32], the relationship between $\mathrm{VO}_{2}$ and cardiac output $(\mathrm{CO})$ is described as: $\mathrm{VO} 2=\mathrm{CO} * \mathrm{a}-$ $\mathrm{vO} 2$ diff (a-vO $\mathrm{v}_{2}$ diff:arteriovenous oxygen difference), where $\mathrm{CO}$ is calculated using the equation: $C O=S V * H R$.

Therefore, the increase in $\mathrm{CO}$ during exercise largely reflects the increase in $\mathrm{VO}_{2}$. Previous studies have shown that SV increases when starting exercise, but rapidly reaches a plateau [33-35]. Therefore, the increase in CO during exercise is due to an increase in HR and SV. On the other hand, SV also increases during lying rest [33, 34]. If the HR during lying rest is set as baseline, the relationship between $\mathrm{HR}$ and $\mathrm{CO}$ would less likely be affected by the changes in SV; therefore, HR should be proportional to $\mathrm{CO}$. In combination, these factors possibly affected the superiority of $\% \mathrm{HRR}_{\text {sleeping }}$ observed in the present study. However, the inaccuracy of $\% \mathrm{HRR}_{\text {sitting }}$ in this study was inconsistent with previous studies [10-12], possibly because our results are condition-specific. The present experiment was performed in a hospital environment, and it is possible that the measurements by "white coat" health professionals yielded relatively higher resting $\mathrm{HR}$, as shown in the previous studies [36, 37]. Thus, the measurement errors in HR values taken while patients were awake could be less evident in the other situations. Despite this, the results presented the validity in using 


\section{Working days}

\section{Holidays}

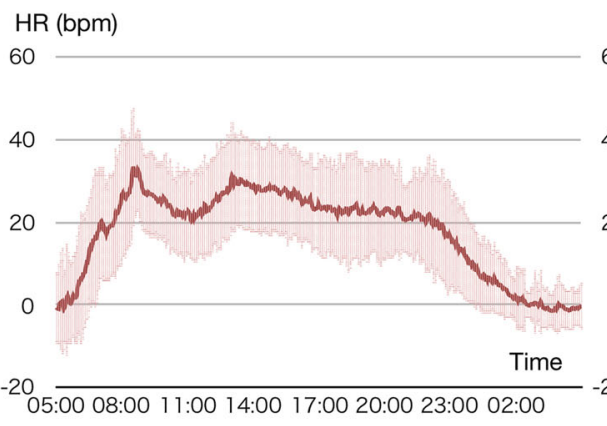

$\mathrm{HR}(\mathrm{bpm})$

\section{Participant A}

\section{Participant B}

\section{HR (bpm)}

60

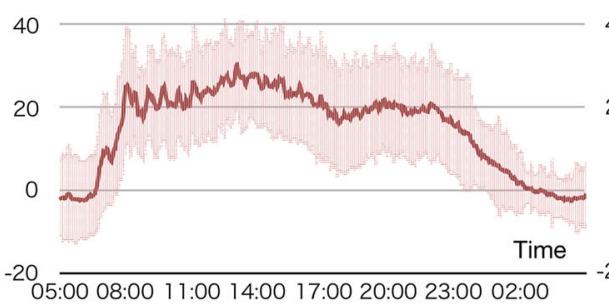

$\mathrm{HR}$ (bpm) 60

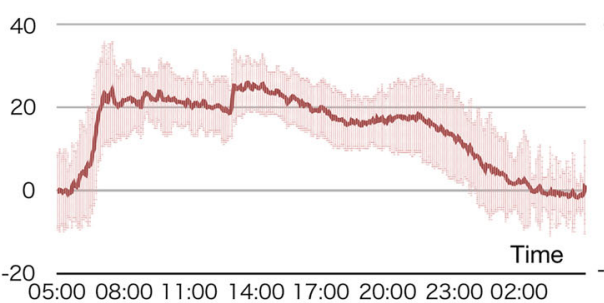

60

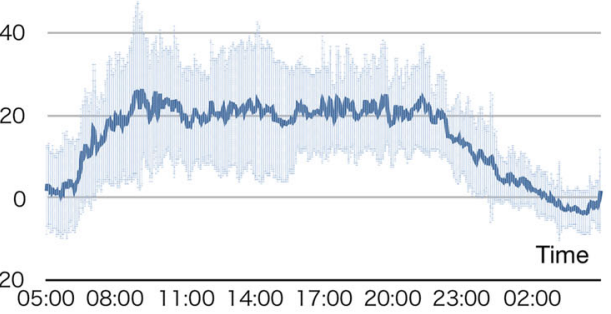

HR (bpm)

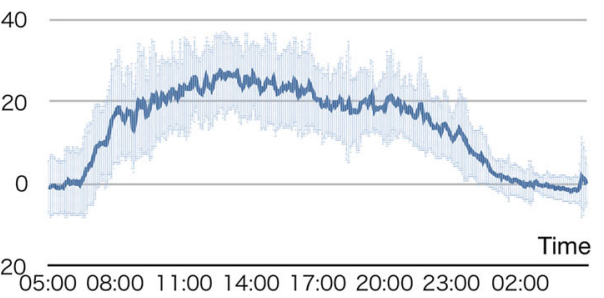

$\mathrm{HR}$ (bpm)

60

40

20

0

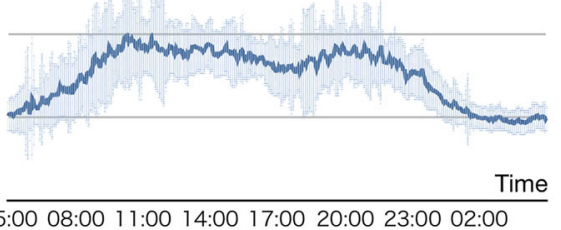

Fig. 2 Ensemble average of daily \%HRR in working days and holidays of three, participants a-c. The time course of \%HRR of three individuals in working days and holidays are presented. The solid line represents the ensemble average of all the measurement period and the light-colored band represents standard deviation. HR, heart rate; \%HRR, percent heart rate reserve

resting $\mathrm{HR}$ during sleep and indicated that it may be a pragmatic solution for the unpredictable and undesirable variability of resting $\mathrm{HR}$ in awake conditions.

As the validity study indicated the validity of the sleeping HR-based exercise intensity calculation, a $24 / 7$ measurement of exercise intensity was performed. The observation of 180 consecutive days of measurement shows the difference in the total amount of exercise intensity between working days and holidays.

The average exercise intensity during daytime ranged from 21 to $26 \%$; this range is consistent with previous studies and demonstrates that the average exercise intensity during working time is approximately $15-30 \%$, which includes different occupations, such as office workers or cleaners $[38,39]$.
The continuous observation of exercise intensity may enable the accurate estimation of energy expenditure $(\mathrm{EE})$, which would also make the nutrition control more precise. Although previous studies have reported limitations in estimation of EE with wearable devices [40-42], the combination of HR measurement with accelerometry may improve the accuracy of EE estimation with the wearable devices $[43,44]$.

In addition, the continuous measurement of HR may also be used to manage the amount of exercise performed by rehabilitation patients; for example, continuous HR measurement could be useful in treating patients with problems in exercise tolerance and related functions. Exercise training is considered to improve exercise tolerance function, especially in patients suffering from chronic 
heart failure, chronic obstructive pulmonary disease (COPD), or chronic kidney failure [45-47]. The combination of using wearable monitoring systems and sleeping HR-based exercise estimation would enable easy monitoring of daily exercise that may possibly improve the management of physical activity and nutrition.

\section{Limitations}

This study has some limitations. First, the hitoe wear is relatively tight compared to a usual T-shirt as the electrode should be attached on the skin. This may have affected the HR measurement during sleep. The influence of the comfortability of the wear and HR measurement during sleep should be further investigated.

The sample size of this study may also be considered a limitation. In this study, the number of participants was 12 , and for each participant, repeated measurements during treadmill testing and 6MWT were performed. The total number of data points in these experiments with repeated measurement were 64 and 36 in treadmill testing and $6 \mathrm{MWT}$, respectively. The previous studies comparing $\% \mathrm{HRR}$ and $\% \mathrm{VO}_{2} \mathrm{R}$ show strong correlation between these two values; on the other hand, they display a large variety in extent of agreement, which ranges from 20 to $30 \%$ at its largest $[10,11]$. Considering that the \%HRR in this experiment would be at similar levels in terms of agreement with $\mathrm{VO}_{2} \mathrm{R}$, we set the maximum allowed difference between the methods to $25 \%$. In this study, the pair with smallest difference was the $\% \mathrm{VO}_{2} \mathrm{R}$ and $\% \mathrm{HRR}_{\text {sleeping }}$ in treadmill testing, whose mean and standard deviation of the difference were 1.7 and $7.7 \%$, respectively. According to the formula provided by $\mathrm{Lu}$ et al., the required sample size for an alpha risk of 0.05 and a power of $80 \%$ would be 26 , and our sample size satisfies this requirement [48]. There may be still some discussion whether this is really a sufficient sample size, because the sample size is based on the repeated measurements, and not on the individual samples. There is no preceding study on sample size using Bland Altman plot with repeated measurements. Nonetheless, the present result would be at least meaningful to indicate the possible superiority of the sleeping HR-based \%HRR calculation to that calculated with sitting $H R$, which is the widely accepted methodology in clinical practice.

\section{Conclusions}

In the present study, \%HRR calculated with the resting HR during sleep was validated with exercise intensity calculations by $\% \mathrm{VO}_{2} \mathrm{R}$. This simplified method may be useful for the daily measurement of exercise intensity using wearable systems, realizing a calibration-less, whole-day measurement model of exercise intensity, which would facilitate further understanding of the effects of exercise on daily activities.

\begin{abstract}
Abbreviations
\%HRR: Percent heart rate reserve; \%HRR ${ }_{\text {lying: }} \% \mathrm{HRR}$ while lying;

\%HRR $\mathrm{H}_{\text {sitting: }} \% \mathrm{HRR}$ while sitting; \%HRR $\mathrm{H}_{\text {sleeping: }}$ \%HRR while sleeping;

$\% \mathrm{VO}_{2} \mathrm{R}$ : Percent $\mathrm{VO}_{2}$ reserve; $6 \mathrm{MWT}$ : 6-min walk test; ANOVA: Analysis of

variance; $\mathrm{a}-\mathrm{VO}_{2}$ dif: Arteriovenous oxygen difference; $\mathrm{Cl}$ : Confidence interval;

CO: Cardiac output; COPD: Chronic obstructive pulmonary disease;

EE: Energy expenditure; HR: Heart rate; $H R_{\text {lying: Heart rate while lying; }}$

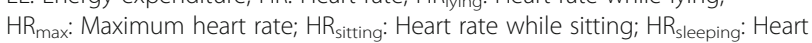

rate while sleeping; LOA: Limits of agreement; SD: Standard deviation;

$\mathrm{SV}$ : Stroke volume; $\mathrm{VO}_{2}$ : Oxygen consumption
\end{abstract}

\section{Acknowledgements}

The authors would like to thank Mr. Kenta Maruyama, for his technical assistance in data analysis.

\section{Authors' contributions}

$\mathrm{HM}$ and MM contributed to the concept and design of the study; HM, YA, TS, Al, EH and TO performed the experiments; HM, MM, YO, HK, YA, TS and ES analysed the data; HM, MM, YO, HK and ES contributed to interpreting the results; and $\mathrm{HM}, \mathrm{MM}, \mathrm{YO}, \mathrm{HK}, \mathrm{TO}$ and ES wrote and edited the manuscript. All authors provided critical feedback and helped shape the research, analysis, and final version of the manuscript. All authors read and approved the final manuscript.

\section{Funding}

The authors received no specific funding for this work.

\section{Availability of data and materials}

The datasets used and/or analysed during the current study are available from the corresponding author on reasonable request.

\section{Ethics approval and consent to participate}

The study protocol was approved by the Medical Ethics Committee of Fujita Health University. All participants provided written informed consent before participation.

\section{Consent for publication}

Not applicable

\section{Competing interests}

The authors declare that they have no competing interests.

\section{Author details}

${ }^{1}$ Department of Rehabilitation Medicine I, School of Medicine, Fujita Health University, Toyoake, Japan. ${ }^{2}$ Department of Rehabilitation Medicine, Fujita Health University Hospital, Toyoake, Japan. ${ }^{3} \mathrm{NTT}$ Device Innovation Center, NTT Basic Research Laboratories, NTT Corporation, Atsugi, Japan.

Received: 24 April 2019 Accepted: 9 October 2019

Published online: 04 November 2019

\section{References}

1. Garber CE, Blissmer B, Deschenes MR, Franklin BA, Lamonte MJ, Lee IM, et al. American College of Sports Medicine position stand. Quantity and quality of exercise for developing and maintaining cardiorespiratory, musculoskeletal, and neuromotor fitness in apparently healthy adults: guidance for prescribing exercise. Med Sci Sports Exerc. 2011;43:1334-59.

2. Thompson PD, Arena R, Riebe D, Pescatello LS. ACSM's new preparticipation health screening recommendations from ACSM's guidelines for exercise testing and prescription, ninth edition. Curr Sports Med Rep. 2013;12:215-7.

3. Jones AM, Vanhatalo A, Burnley M, Morton RH, Poole DC. Critical power: implications for determination of $\mathrm{V} \mathrm{O} 2 \mathrm{max}$ and exercise tolerance. Med Sci Sports Exerc. 2010;42:1876-90.

4. Bruce RA, Kusumi F, Hosmer D. Maximal oxygen intake and nomographic assessment of functional aerobic impairment in cardiovascular disease. Am Heart J. 1973:85:546-62.

5. Balke B, Ware RW. An experimental study of physical fitness of air force personnel. U S Armed Forces Med J. 1959;10:675-88.

6. Colberg SR, Swain DP, Vinik AI. Use of heart rate reserve and rating of perceived exertion to prescribe exercise intensity in diabetic autonomic neuropathy. Diabetes Care. 2003;26:986-90. 
7. Swain DP. Energy cost calculations for exercise prescription: an update. Sports Med. 2000;30:17-22.

8. Karvonen MJ, Kentala $\mathrm{E}$, Mustala $\mathrm{O}$. The effects of training on heart rate; a longitudinal study. Ann Med Exp Biol Fenn. 1957:35:307-15.

9. Brawner CA, Keteyian SJ, Ehrman JK. The relationship of heart rate reserve to VO2 reserve in patients with heart disease. Med Sci Sports Exerc. 2002;34: 418-22.

10. Cunha FA, Midgley AW, Monteiro WD, Farinatti PT. Influence of cardiopulmonary exercise testing protocol and resting VO (2) assessment on \%HR (max), \%HRR, \%VO (2max) and \%VO (2) R relationships. Int J Sports Med. 2010;31:319-26.

11. Swain DP, Leutholtz BC. Heart rate reserve is equivalent to \%VO2 reserve, not to \%VO2max. Med Sci Sports Exerc. 1997;29:410-4.

12. Swain DP, Leutholtz $B C$, King ME, Haas LA, Branch JD. Relationship between $\%$ heart rate reserve and \% VO2 reserve in treadmill exercise. Med Sci Sports Exerc. 1998;30:318-21.

13. Gellish RL, Goslin BR, Olson RE, McDonald A, Russi GD, Moudgil VK. Longitudinal modeling of the relationship between age and maximal heart rate. Med Sci Sports Exerc. 2007;39:822-9.

14. Brooks D, Solway S, Gibbons WJ. ATS statement on six-minute walk test. Am J Respir Crit Care Med. 2003:167:1287.

15. Coote JH. Respiratory and circulatory control during sleep. J Exp Biol. 1982; 100:223-44.

16. Bai Y, Hibbing P, Mantis C, Welk GJ. Comparative evaluation of heart rate-based monitors: apple watch vs Fitbit charge HR. J Sports Sci. 2018:36:1734-41.

17. Thomson EA, Nuss K, Comstock A, Reinwald S, Blake S, Pimentel RE, et al. Heart rate measures from the apple watch, Fitbit charge HR 2, and electrocardiogram across different exercise intensities. J Sports Sci. 2019;37:1411-19.

18. Matsuura $H$, Mukaino $M$, Ogasawara T, Aoshima $Y$, Suzuki T, Inukai A, et al. Preliminary study on activity monitoring for over 24 hours among stroke patients in a rehabilitation ward. Jpn J Compr Rehabil Sci. 2019;10:37-41.

19. de Zambotti M, Baker FC, Willoughby AR, Godino JG, Wing D, Patrick K, et al. Measures of sleep and cardiac functioning during sleep using a multisensory commercially-available wristband in adolescents. Physiol Behav. 2016;158:143-9.

20. Haghayegh S, Khoshnevis S, Smolensky MH, Diller KR. Accuracy of PurePulse photoplethysmography technology of Fitbit charge 2 for assessment of heart rate during sleep. Chronobiol Int. 2019;36:927-33.

21. Duscha BD, Slentz CA, Johnson JL, Houmard JA, Bensimhon DR, Knetzger $\mathrm{KJ}$, et al. Effects of exercise training amount and intensity on peak oxygen consumption in middle-age men and women at risk for cardiovascular disease. Chest. 2005;128:2788-93.

22. van Waart $H$, Stuiver MM, van Harten WH, Geleijn E, Kieffer JM, Buffart LM, et al. Effect of low-intensity physical activity and moderate- to high-intensity physical exercise during adjuvant chemotherapy on physical fitness, fatigue, and chemotherapy completion rates: results of the PACES randomized clinical trial. J Clin Oncol. 2015;33:1918-27

23. Howley ET, Bassett DR Jr, Welch HG. Criteria for maximal oxygen uptake: review and commentary. Med Sci Sports Exerc. 1995;27:1292-301.

24. Altman DG. Practical statistics for medical research. 1st ed. Boca Raton: Chapman and Hall/CRC; 1990.

25. Atkinson G, Nevill AM. Statistical methods for assessing measurement erro (reliability) in variables relevant to sports medicine. Sports Med. 1998;26:217-38.

26. Bland JM, Altman DG. Agreement between methods of measurement with multiple observations per individual. J Biopharm Stat. 2007;17:571-82.

27. Zou GY. Confidence interval estimation for the Bland-Altman limits of agreement with multiple observations per individual. Stat Methods Med Res. 2013;22:630-42

28. Grassi G, Vailati S, Bertinieri G, Seravalle G, Stella ML, Dell'Oro R, et al. Heart rate as marker of sympathetic activity. J Hypertens. 1998;16:1635-9.

29. Pierpont $\mathrm{GL}$, Stolpman DR, Gornick CC. Heart rate recovery post-exercise as an index of parasympathetic activity. J Auton Nerv Syst. 2000;80:169-74.

30. Anderson EA, Sinkey CA, Mark AL. Mental stress increases sympathetic nerve activity during sustained baroreceptor stimulation in humans. Hypertension. 1991;17(4 Suppl):III43-9.

31. Savin WM, Davidson DM, Haskell WL. Autonomic contribution to heart rate recovery from exercise in humans. J Appl Physiol Respir Environ Exerc Physiol. 1982;53:1572-5.

32. Fick A. The output of the heart. J Physikalisch-Medicinische Gesellschaft. 1870;2:XVI.
33. Bevegard S, Holmgren A, Jonsson B. The effect of body position on the circulation at rest and during exercise, with special reference to the influence on the stroke volume. Acta Physiol Scand. 1960;49:279-98.

34. Wang Y, Marshall RJ, Shepherd JT. The effect of changes in posture and of graded exercise on stroke volume in man. J Clin Invest. 1960;39:1051-61.

35. Granath A, Jonsson B, Strandell T. Circulation in healthy old men, studied by right heart catheterization at rest and during exercise in supine and sitting position. Acta Med Scand. 1964;176:425-46.

36. Mancia G, Bertinieri G, Grassi G, Parati G, Pomidossi G, Ferrari A, et al. Effects of blood-pressure measurement by the doctor on patient's blood pressure and heart rate. Lancet. 1983;2:695-8.

37. Mancia G, Parati G, Pomidossi G, Grassi G, Casadei R, Zanchetti A. Alerting reaction and rise in blood pressure during measurement by physician and nurse. Hypertension. 1987;9:209-15.

38. Balogh I, Orbaek P, Ohlsson K, Nordander C, Unge J, Winkel J, et al. Selfassessed and directly measured occupational physical activities-influence of musculoskeletal complaints, age and gender. Appl Ergon. 2004;35:49-56.

39. Makowiec-Dabrowska T. Stress and strain during work among women performing different work tasks. Int J Occup Med Environ Health. 1994;7:323-43.

40. Thiebaud RS, Funk MD, Patton JC, Massey BL, Shay TE, Schmidt MG, et al. Validity of wrist-worn consumer products to measure heart rate and energy expenditure. Digit Health. 2018:4:2055207618770322.

41. Shcherbina A, Mattsson CM, Waggott D, Salisbury H, Christle JW, Hastie T, et al. Accuracy in wrist-worn, sensor-based measurements of heart rate and energy expenditure in a diverse cohort. J Pers Med. 2017;7:3.

42. Wallen MP, Gomersall SR, Keating SE, Wisloff U, Coombes JS. Accuracy of heart rate watches: implications for weight management. PLoS One. 2016; 11:e0154420

43. Crouter SE, Churilla JR, Bassett DR Jr. Accuracy of the Actiheart for the assessment of energy expenditure in adults. Eur J Clin Nutr. 2008;62:704-11.

44. Yang L, Lu K, Forsman M, Lindecrantz K, Seoane F, Ekblom O, et al. Evaluation of physiological workload assessment methods using heart rate and accelerometry for a smart wearable system. Ergonomics. 2019;62:694-705.

45. Belardinelli R, Georgiou D, Scocco V, Barstow TJ, Purcaro A. Low intensity exercise training in patients with chronic heart failure. J Am Coll Cardiol. 1995;26:975-82

46. Casaburi R, Porszasz J, Burns MR, Carithers ER, Chang RS, Cooper CB. Physiologic benefits of exercise training in rehabilitation of patients with severe chronic obstructive pulmonary disease. Am J Respir Crit Care Med. 1997;155:1541-51.

47. Painter $P$. The importance of exercise training in rehabilitation of patients with end-stage renal disease. Am J Kidney Dis. 1994;24(1 Suppl 1):S2-9 discussion S31-2.

48. Lu MJ, Zhong WH, Liu YX, Miao HZ, Li YC, Ji MH. Sample size for assessing agreement between two methods of measurement by Bland-Altman method. Int J Biostat. 2016;12:2.

\section{Publisher's Note}

Springer Nature remains neutral with regard to jurisdictional claims in published maps and institutional affiliations.

Ready to submit your research? Choose BMC and benefit from:

- fast, convenient online submission

- thorough peer review by experienced researchers in your field

- rapid publication on acceptance

- support for research data, including large and complex data types

- gold Open Access which fosters wider collaboration and increased citations

- maximum visibility for your research: over $100 \mathrm{M}$ website views per year

At BMC, research is always in progress.

Learn more biomedcentral.com/submission 